INTERNATIONAL HIGHER EDUCATION NUMBER 65 FALL, 2011

\title{
Pages $5-7$
}

English and the Rest: Understanding the Languages of Science

Jorge Balán

Jorge Balán is a senior research scholar, School of International and Public Affairs, Columbia University. E-mail: jb3369@columbia.edu.

The dominance of English in international academic publications has increased manifolds during the last few decades. The vast majority of indexed science journals, including those previously published in other languages, have shifted to English; less marked among traditional players has been the change from French and Russian. Journals prefer English to acquire a broader international authorship and readership and to reach higher impact (number of citations). English-language journals have increased the proportion of authors from nonAnglo countries-although proportionally their communities are underrepresented-while non-English-language journals have become mostly national or regional in scope.

Yet, the number of scientific publications in languages other than English keeps growing even more rapidly as the scientific communities in non-Anglo countries (for instance, in China, Indonesia, Iran, Turkey, southern Europe, and Latin America) expand and diversify. The proportion of all scientific periodicals worldwide that are published in English is actually declining. However, the vast majority of high-impact journals are in English. Medicine is a good example of both trends: the development of a central core of the most important medical 
journals worldwide published almost entirely in English and indexed in the US National Library of Medicine's database, Medline; and the rapidly expanding peripheries published in other languages, serving continuing medical education or research on the delivery of care within the local national health systems. These peripheries include formerly dominant languages in the world of medical research, such as German and French, and many others. Communities of professionals and scientists use the prevailing national languages to communicate among themselves, with policymakers, and with clients. English is the main global lingua franca of scientific communication, but there are many other languages of a national or international scope-such as mandarin Chinese or Bahasa Indonesia, among the former, and Spanish or French, among the latter.

English dominance and the distinction between central and peripheral languages are less marked in the social sciences and the humanities. A smaller majority of international indexed journals are published in English, and social sciences and humanities-based indexes differ markedly in their language coverage. Many journals offer now translated versions of articles in English, side by side with original versions of articles in other languages. In several countries, notably China, English-language journals are now published as a venue for previously published articles in the national language. Much less common in social sciences and humanities is the shift of journals to English, although it has increased in some disciplines, such as psychology. In many of these fields (e.g., literature, history, and anthropology) books are still more important than journal articles. Books are published first in the national language; few are eventually translated into English or other languages. 
Social sciences and humanities scholars are under pressure to publish in English, in order to become internationally visible and to contribute to the global ranking of their countries and institutions, measured through indexed publications of high impact. However, these scholars are counterbalanced by the pressure to reach rapidly growing domestic academic and policy communities. In many countries, internationalization and language policies run in opposite directions, the first favoring English and the other a national or regional language.

\section{Costs And Risks of International (ENglish) Publication}

The underrepresentation of non-native-English-speaking scholars in international English journals attests to the many disadvantages encountered when compared to native-English-speaker authors. Most cited problems relate to the costs in time and effort, since typically non-native researchers in all disciplines need more time to turn their papers in English, often relying on professional translators. International indexed journals often request authors to have papers reviewed by native speakers in order to turn them into a "standard" English-language version. Research on science journals found striking differences in acceptance rates for non-native compared to native authors as well as longer processes of revision and resubmission, adding to the costs and lowering the productivity of researchers who are non-native-English speakers.

Scholars in elite universities in developing countries, such as China, usually report cross-pressures. On the one hand, publication in English for an international audience, preferably in international indexed journals, is supported by academic administrations focused on international rankings. On the other, 
publication in the national language is required to reach domestic audiences and obtain greater legitimacy in public opinion and policymaking circles. Domestic English-language translations offer a chance of dual publication but lack the prestige of international indexed journals.

In the Arab world, according to Sari Hanafi, the main dilemma faced by social scientists is to publish globally and perish locally versus to publish locally and perish globally. Elite universities, where teaching is often conducted in English or French, assess faculty productivity in terms of academic publications in international peer-reviewed journals using international standards. Local or regional publication, in Arab or other languages, does not count for promotion, thus drawing research away from those issues that might be deemed important by local or regional audiences. National public universities, on the other hand, are locally oriented-faculty members publish locally, in Arabic and thus perish globally. This segmentation by language and domestic/international focus seems to affect entire disciplines, such as economics and psychology, throughout the developing world.

\section{INTERNATIONAL UNIVERSITIES AND THE REST OF THE WORLD}

Many universities in western Europe, East Asia, or the Middle East are now considering themselves truly international in that their student body and their faculty come from all over the world. These international universities tend to teach in English or, specifically, in some variety of English—often a "lingua franca" that departs in significant ways from "normal" academic English as practiced in the English-speaking countries. Furthermore, the adoption of English as a language of instruction does not preclude the use of other languages 
for interaction out of the classroom. Scandinavian researchers, for instance, have been studying the uses of many languages, in and out of the classroom, in international universities within the region. Many have also noticed that lingua franca English has notorious differences between countries and regions, so that international universities in the Netherlands, Singapore, or China may actually differ considerably in the languages used in different settings or from "standard" English. Since international universities are meant to be part of the world of international research, where publications are dominated by English, a pressure still exists toward standardization in the written language. In the United States and the United Kingdom, manual styles have been prepared to guide international doctoral students writing their dissertations in English-in conformity with a way to present theory, methods, data, and conclusions. Should these standards be adopted by international universities in non-English-speaking countries, the diversity associated with language and cultural tradition would be lost.

The vast majority of universities and academic programs outside Englishspeaking countries, which are enrolling a growing student body, conduct their everyday activities in the national or local languages. This is the case both for undergraduate and professional education. English is becoming the preferred second language for a majority of students worldwide, but it is not the language in which they are educated or trained for the professions embedded in national realities. With few exceptions-in scientific disciplines and mathematics-at the graduate level, a majority of the bibliography used by those students tends to be in the national languages, either original or in translation. Last, but not least, the increased use of the Internet for academic purposes also is reflecting the growth 
of languages other than English in the world of electronic communication, until recently dominated by the English language.

\section{CONCLUSION}

Languages other than English are here to stay in the world of higher education and research. Globalization requires, in order to be effective, a greater effort in translation, so that access to the many varieties of scholarly production becomes more effectively available to readers worldwide. Certainly, translation into English is a means to expand accessibility both in English-speaking countries and elsewhere. 